\title{
Author Correction: Evaluation of Weight Loss Indicators and Laparoscopic One-Anastomosis Gastric Bypass Outcomes
}

Miguel A. Carbajo ${ }^{1}$, Jose M. Jiménez $\mathbb{D}^{1,2,3,4}$, Enrique Luque-de-León ${ }^{1}$, María-José Cao ${ }^{2,3}{ }^{2}$, María López ${ }^{2,4}$, Sara García ${ }^{4}$ \& María-José Castro $\mathbb{D}^{1,2,3}$

Correction to: Scientific Reports https://doi.org/10.1038/s41598-018-20303-6, published online 31 January 2018

In the original version of this Article, María-José Cao was incorrectly affiliated with:

'Centre of Excellence for the Study and Treatment of Diabetes and Obesity, Valladolid, Spain'

and

'Nursing Faculty, University of Valladolid, Valladolid, Spain'

and

'Endocrinology and Clinical Nutrition Research Centre (ECNRC), University of Valladolid, Valladolid, Spain'.

The correct affiliations are below:

'Nursing Faculty, University of Valladolid, Valladolid, Spain'

and

'Endocrinology and Clinical Nutrition Research Centre (ECNRC), University of Valladolid, Valladolid, Spain'.

(i) Open Access This article is licensed under a Creative Commons Attribution 4.0 International License, which permits use, sharing, adaptation, distribution and reproduction in any medium or format, as long as you give appropriate credit to the original author(s) and the source, provide a link to the Creative Commons license, and indicate if changes were made. The images or other third party material in this article are included in the article's Creative Commons license, unless indicated otherwise in a credit line to the material. If material is not included in the article's Creative Commons license and your intended use is not permitted by statutory regulation or exceeds the permitted use, you will need to obtain permission directly from the copyright holder. To view a copy of this license, visit http://creativecommons.org/licenses/by/4.0/.

(c) The Author(s) 2018

${ }^{1}$ Centre of Excellence for the Study and Treatment of Diabetes and Obesity, Valladolid, Spain. ${ }^{2}$ Nursing Faculty, University of Valladolid, Valladolid, Spain. ${ }^{3}$ Endocrinology and Clinical Nutrition Research Centre (ECNRC), University of Valladolid, Valladolid, Spain. ${ }^{4}$ Castilla-León Regional Healthcare Management (Sacyl), Valladolid, Spain. Miguel A. Carbajo and Jose M. Jiménez contributed equally to this work. Correspondence and requests for materials should be addressed to M.A.C. (email: doctorcarbajo@obesos.info) or J.M.J. (email: jsmrjimenez@gmail.com) 